\title{
Seguridad De Ciclistas Circulando En Pelotón En Carretera Convencional
}

\author{
Carlos Llorca \\ Profesor Ayudante, Universitat Politècnica de València, España \\ Jorge Serra Planelles \\ Estudiante ICCP, UPV, España \\ Alfredo García \\ Catedrático, UPV, España
}

\section{RESUMEN}

La afluencia de ciclistas aficionados en carreteras convencionales para la práctica de actividades deportivas es muy notable, llegando en algunos casos a que la intensidad de tráfico ciclista supere a la de tráfico motorizado. Sin embargo, la presencia de ciclistas compartiendo la infraestructura con vehículos supone un problema para la seguridad vial. Los accidentes relacionados con alcances, adelantamientos o salidas de vía tienen consecuencias muy graves, debido a la diferencia de velocidad y tamaño entre bicicletas y vehículos y a la falta de protección del cuerpo del ciclista ante un accidente.

En particular, la disposición de los ciclistas al circular en la vía (individualmente, en línea, en paralelo, etc.) puede afectar a su visibilidad, capacidad de reacción y margen de seguridad disponible en las maniobras de adelantamiento realizadas por el tráfico motorizado. Esta investigación caracterizó las trayectorias y la posible invasión del sentido contrario de los vehículos a motor, cuando adelantaron a ciclistas dispuestos en diversas configuraciones de pelotón (individual, 2 en línea, 2 en paralelo).

Para ello, se hizo circular a tres ciclistas, en configuraciones previamente fijadas, por un tramo de carretera convencional. Las bicicletas fueron equipadas con distanciómetros láser, medidores de velocidad, GPS cámaras de video, y un pulsador mediante el que los ciclistas valoraban el riesgo percibido cada vez que un vehículo motorizado les rebasaba. El análisis de los datos obtenidos permitió comparar, en las diversas configuraciones de pelotón, la distribución de las distancias laterales durante el adelantamiento, las velocidades de los vehículos que adelantan, y el nivel de riesgo percibido.

Los resultados obtenidos proporcionaron criterios para evaluar los riesgos de circular en cada una de las configuraciones, en base a características objetivas (separación, velocidad o tipo de vehículo), y subjetivas (percepción de riesgo).

\section{INTRODUCCIÓN}

En España, la presencia de ciclistas en la calzada de carreteras interurbanas es un fenómeno 
muy habitual, generalmente asociado a la práctica de actividades deportivas, aunque también relacionada con la movilidad diaria. Además, el número de ciclistas ha aumentado considerablemente en los últimos años, de forma paralela a lo sucedido en áreas urbanas.

Desde el punto de vista de la seguridad vial, la presencia de ciclistas en la vía supone una problemática que causó, en 2013, más de 1500 accidentes con víctimas, 297 heridos graves y 45 muertes. Comparando estos datos con los correspondientes a zonas urbanas, se observa una mayor gravedad, dado que en las carreteras se detectaron solo el $26 \%$ de los accidentes con víctimas, pero el $45 \%$ de heridos graves y el $65 \%$ de muertes. Las mayores velocidades relativas entre bicicleta y vehículo son las responsables de esta mayor gravedad, que también identificaron otros autores, como Boufous et al. (2012).

La circulación de bicicletas en carreteras convencionales (donde se concentra la gran mayoría del tráfico interurbano ciclista) y su interacción con vehículos a motor está regulada por el Reglamento General de Circulación (Ministerio del Interior, 2003). Las bicicletas deben circular por el arcén, si existe, o lo más próximas al borde derecho de la calzada. Se permite la circulación de dos ciclistas en paralelo siempre que exista visibilidad suficiente. Además, los vehículos a motor deben guardar una distancia lateral de 1,5 m al adelantar a ciclistas, pudiendo rebasar el sentido contrario siempre que se disponga de visibilidad suficiente.

(Llorca et al., 2015) analizaron recientemente el fenómeno del adelantamiento de vehículos a motor a una bicicleta aislada en carreteras convencionales. Para ello, desarrollaron una bicicleta instrumentalizada, equipada con distanciómetros y velocímetros láser, así como cámaras de video y un receptor GPS. La bicicleta realizó diversos recorridos de ida y vuelta por los tramos seleccionados, caracterizando los adelantamientos de vehículos a motor, y siguiendo la metodología propuesta anteriormente por (Chapman and Noyce, 2012; Love et al., 2012; Walker, 2007). Las conclusiones de aquél estudio, aplicado a 7 carreteras en el entorno de Valencia, mostraron que un $36 \%$ de las maniobras, la distancia lateral libre, entre el retrovisor del vehículo y el manillar de la bicicleta, era inferior al mínimo de $1.5 \mathrm{~m}$ definido en el Reglamento General de Circulación. Además, como resultado de dicho estudio, se identificaron otros factores adicionales relacionados con el riesgo percibido por el ciclista. Las altas velocidades del vehículo a motor, y la existencia de un alto porcentaje de vehículos pesados, estaban presentes en las localizaciones más peligrosas. Estas variables se relacionan con los efectos aerodinámicos causados por el adelantamiento de un vehículo a velocidad elevada, tal como predijeron (Ata and Langlois, 2011; Corin et al., 2008; Noger et al., 2005; Uystepruyst and Krajnović, 2013).

Todos los estudios anteriores se centraron en una única bicicleta adelantada. Sin embargo, es muy habitual encontrar grupos de ciclistas circulando por las carreteras. Este hecho, puede afectar de forma significativa a la percepción y detección de las bicicletas por parte de los conductores, de modo que les sería más sencillo apercibirse de ellas. Por el contrario, al circular dos ciclistas en paralelo se reduce el espacio físico disponible para realizar el 
adelantamiento de forma segura, por lo que podrían darse más casos de incumplimiento de la regulación acerca de la distancia lateral mínima.

Dado que no existen investigaciones previas relativas a la circulación de ciclistas en paralelo, y en especial, a su interacción con vehículos a motor, el presente estudio desarrolló un método para evaluar la seguridad de adelantamientos a grupos de ciclistas en carretera convencional.

\section{OBJETIVOS}

El objeto principal fue analizar la seguridad vial de los adelantamientos de vehículos a motor a ciclistas circulando en grupos en carreteras convencionales. Para ello, se cumplieron los siguientes objetivos:

- Desarrollo de un método experimental para obtener datos acerca del comportamiento de conductores al adelantar ciclistas en grupo.

- Comparación de la peligrosidad existente en distintas configuraciones del pelotón por medio de variables objetivas y subjetivas.

- Análisis del cumplimiento de la normativa aplicable a la maniobra.

\section{METODOLOGÍA}

Tal como se ha comentado, y a partir de estudios anteriores (Llorca et al., 2015) se empleó un método experimental para observar maniobras de adelantamiento de vehículos a motor a bicicletas. El principio de este método fue el observar las maniobras desde varias bicicletas instrumentalizadas que circulaban realizando recorridos sucesivos de ida y vuelta a lo largo del tramo seleccionado.

\subsection{Equipamiento}

Para obtener los datos necesarios, las bicicletas llevaban instalado un medidor de velocidad y distancia láser, cámaras de video, GPS y un pulsador. Mediante el medidor láser se pudo detectar la distancia lateral y la velocidad relativa del vehículo a motor. Las cámaras de video captaban imágenes de la parte trasera y delantera de la bici, observando el vehículo adelantante y su interacción con el tráfico opuesto. La posición y velocidad de la bici quedó registrada mediante el receptor GPS instalado a bordo. Por último, en cada uno de los adelantamientos, el ciclista accionaba uno de los pulsadores instalados en el manillar. Se dispuso una línea de 5 pulsadores para registrar la percepción del riesgo por parte del ciclista, desde el nivel más bajo (sin riesgo) hasta el más alto (casi-accidente). Esta información se codificó por medio de LED superpuestos en las imágenes de la cámara trasera.

\subsection{Localización}

Para la realización del estudio, se escogió un tramo de la carretera CV-50, entre los PK $76+000$ y $86+000$. Se trata de una carretera convencional que transcurre por terreno ondulado, estando las pendientes por debajo del $3 \%$ en la mayoría del tramo, y disponiendo de una sección 7/10 (con arcenes pavimentados de $1.5 \mathrm{~m}$ de ancho). 


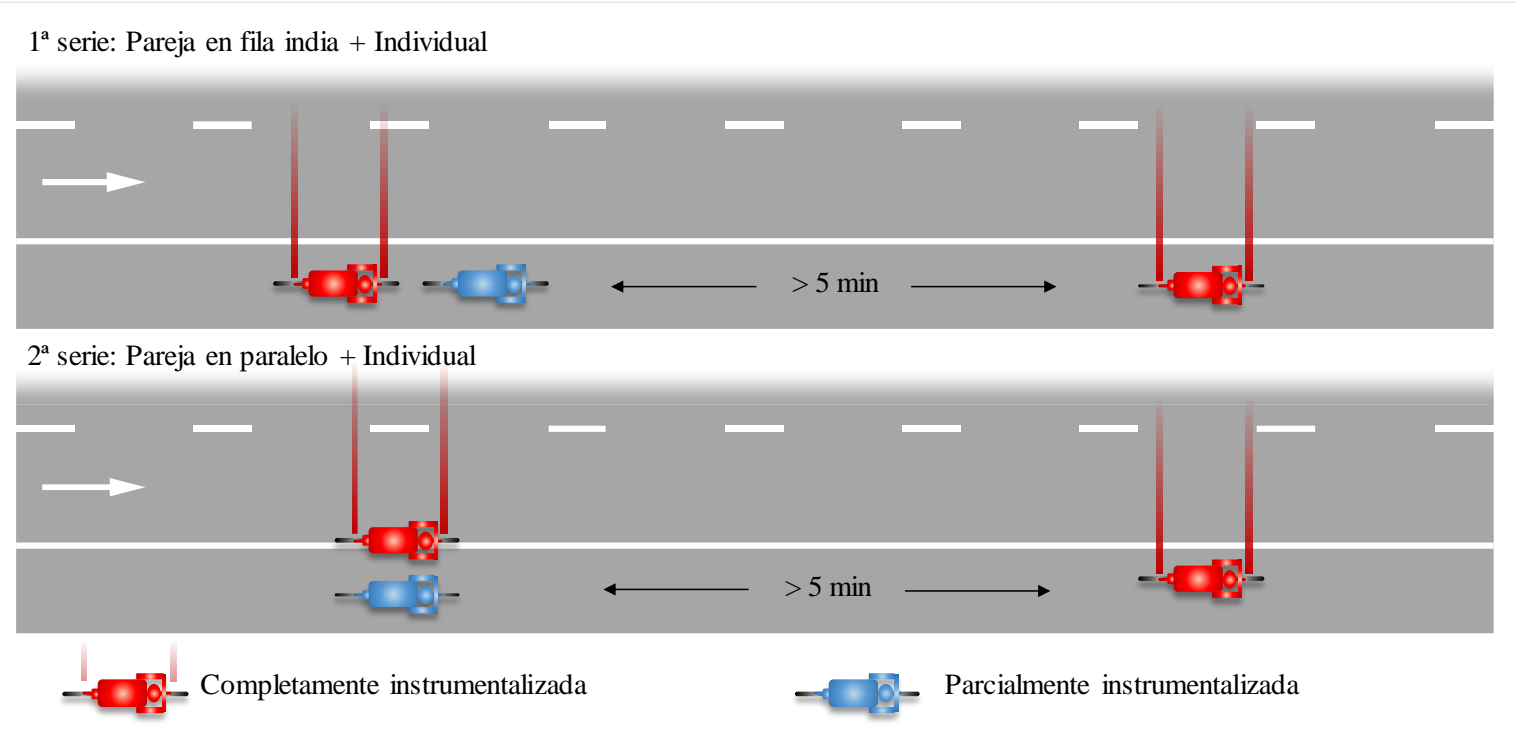

\section{Figura 1. Diseño experimental}

Por otra parte, la velocidad de proyecto en el tramo seleccionado es de $80 \mathrm{~km} / \mathrm{h}$, mientras que el límite de velocidad (genérico) es de $100 \mathrm{~km} / \mathrm{h}$.

\subsection{Diseño experimental}

El experimento se basó en que la bicicleta o bicicletas obtenían, mientras circulaban, los datos correspondientes a las maniobras de adelantamiento que otros vehículos a motor realizaban. Entre los objetivos de la investigación se encontraba la comparación de esta maniobra entre diversas configuraciones del pelotón. Por ello, se dispuso de dos bicicletas completamente instrumentalizadas y una de ellas parcialmente instrumentalizada (solo cámaras de video y pulsadores). Estas bicicletas realizaron los recorridos resumidos en la Figura 1 observando un total de 224 maniobras.

\subsection{Reducción de datos}

A partir de los datos obtenidos, y de acuerdo a los objetivos de esta investigación, se obtuvieron y analizaron las siguientes variables (Figura 2):

- Distancia lateral entre la bicicleta y el vehículo a motor: a partir de la medición del láser, se transformó a una de las siguientes variables:

- Separación bruta $(d)$ : entre el eje de la bicicleta y la carrocería del vehículo.

- Separación neta $(s)$ : entre el borde izquierdo del manillar de la bicicleta y el derecho del retrovisor del vehículo.

- Velocidad relativa $(d V)$ : medida directamente del láser.

- Velocidad de la bicicleta $(V b)$.

- Velocidad del vehículo $(V v=V b+d V)$.

- Tiempo de ocupación del carril contrario.

- Percepción subjetiva del riesgo: obtenida en una escala de Likert de 1 a 5.

- Configuración del pelotón, y posición de la bici analizada dentro del pelotón. 


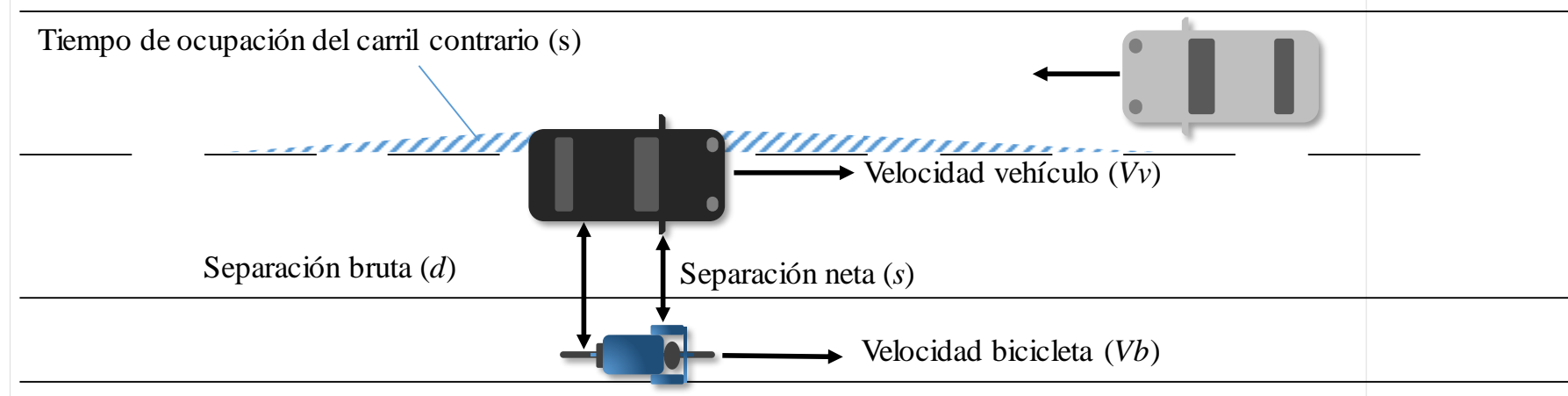

\section{Figura 2. Principales variables del estudio}

Teniendo en cuenta esta última variable, el tratamiento de los datos se realizó de la siguiente forma:

- Cuando la bicicleta circula de forma individual, todos los datos se referían a ella.

- Cuando las bicicletas circulan en pareja y "en paralelo", los datos relativos a la distancia y velocidad relativa se correspondían con la bici instrumentalizada, situada en el interior (próxima al tráfico).

- Cuando las bicicletas circulan en pareja y "en fila india", los datos relativos a la distancia y velocidad relativa se correspondían con la bici completamente instrumentalizada, situada detrás.

Todos los datos correspondientes a la percepción subjetiva de riesgo se trataron de forma individual, pues dependen de los umbrales de riesgo particulares de cada ciclista.

\section{ANÁLISIS}

El análisis de los datos recogidos se centró en la comparación de las principales variables (separación neta, velocidad relativa, ocupación del carril contrario y percepción subjetiva) entre las distintas configuraciones de pelotón. Se trataron por separado los casos correspondientes a un vehículo ligero y a uno pesado realizando los adelantamientos, y se analizaron, únicamente, maniobras aisladas realizadas por vehículos que no estaban en cola.

Del total de 224 maniobras analizadas, 63 fueron en la configuración individual (45 adelantando un vehículo ligero y 18 un vehículo pesado), 59 en fila india (54 adelantando un vehículo ligero y 5 un vehículo pesado) y 102 en paralelo (88 adelantando un vehículo ligero y 14 un vehículo pesado).

Tal como se observa en la Figura 3, la separación lateral neta $(s)$ depende de forma clara de la configuración. En concreto, se observan menores separaciones para el caso de la disposición en paralelo, tal como se había predicho. En cuanto a la velocidad relativa $(d V)$, y tal como queda reflejado en la Figura 4 se observa un menor valor en el caso de circular en fila india, tanto en el caso de vehículos ligeros como pesados. 

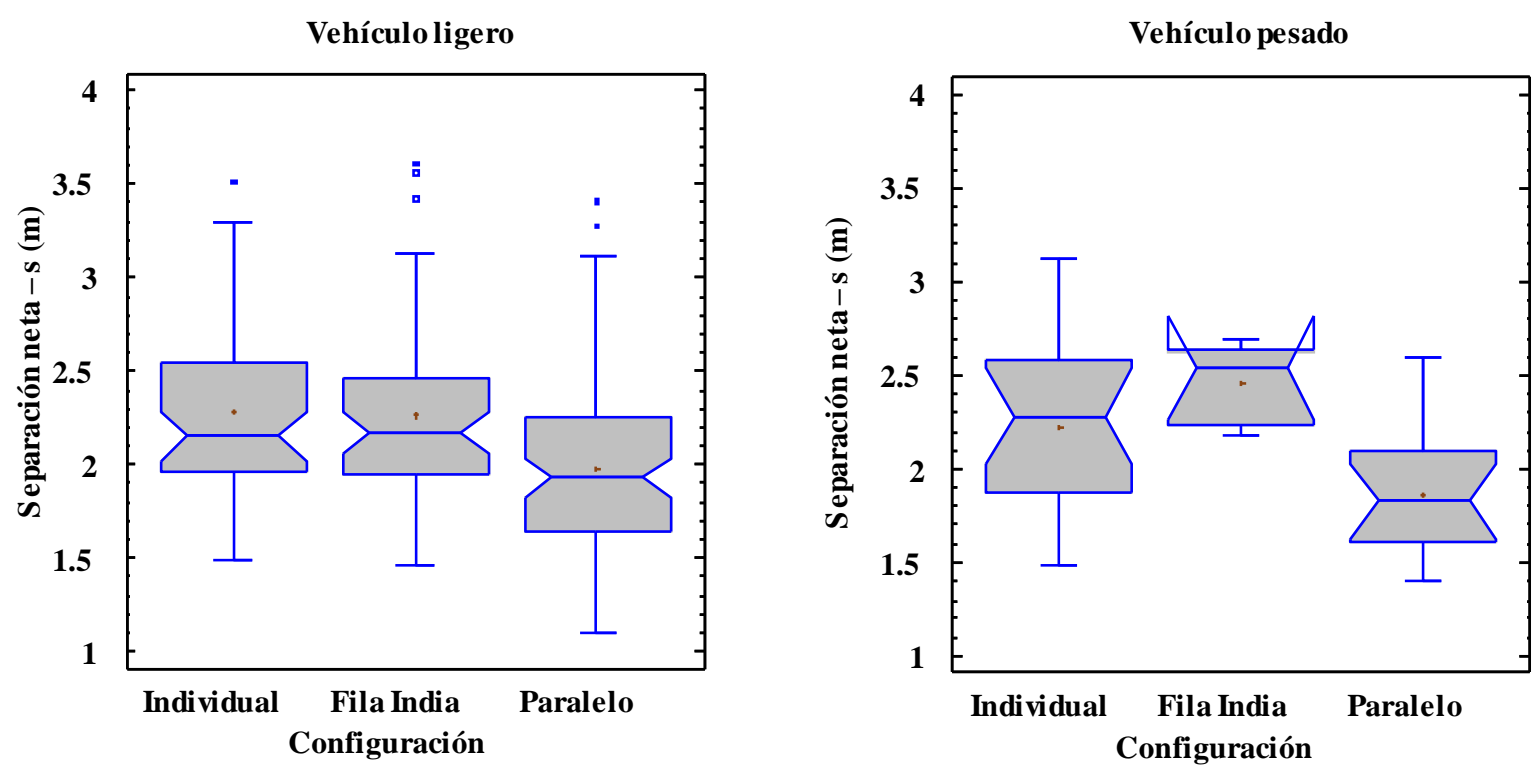

\section{Figura 3. Separación neta}
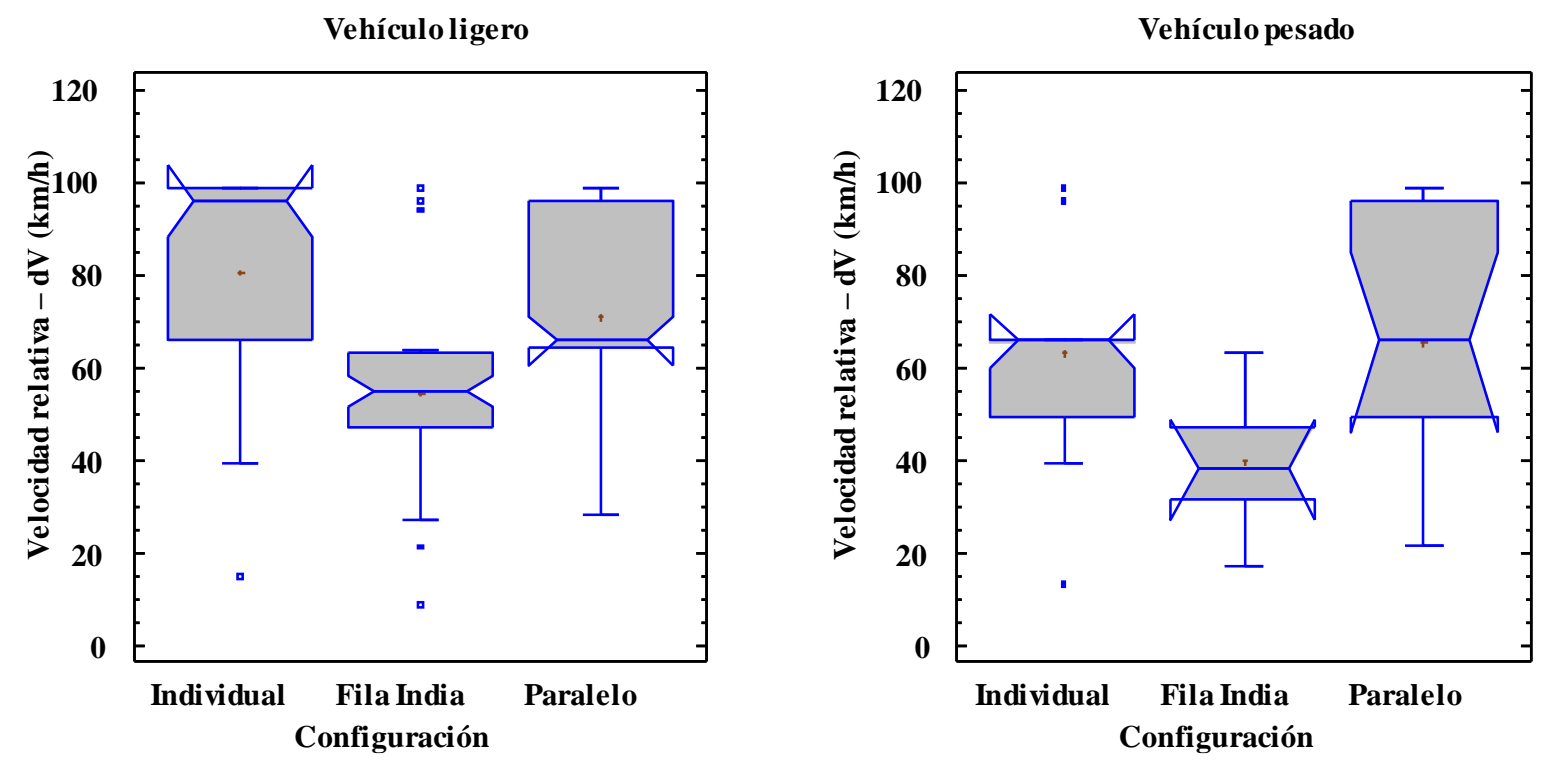

\section{Figura 4. Velocidad relativa}

La ocupación del carril contrario, cuando adelantaba un vehículo ligero, se registró en el $51 \%$ de los casos en configuración individual, en el $70 \%$ de los casos en fila india y en el $56 \%$ de los casos en paralelo. Los valores correspondientes al adelantamiento de un vehículo pesado fueron $77 \%, 100 \%$ y 100\%, respectivamente. En los casos en los que existió ocupación del carril contrario, y de acuerdo a la Figura 5, se observa que, en la configuración en fila india, la duración de dicha ocupación fue mayor.

En la Figura 6 se comparan las percepciones subjetivas de un único ciclista (que circuló de forma individual y en la parte interior - próxima al tráfico - en paralelo) con la separación neta, velocidad, y tipo de vehículo adelantante. A fecha de presentación del presente artículo no se disponía de los datos relativos al resto de ciclistas participantes. De este estudio preliminar, se observa que, en general, una mayor distancia supone un empeoramiento del 

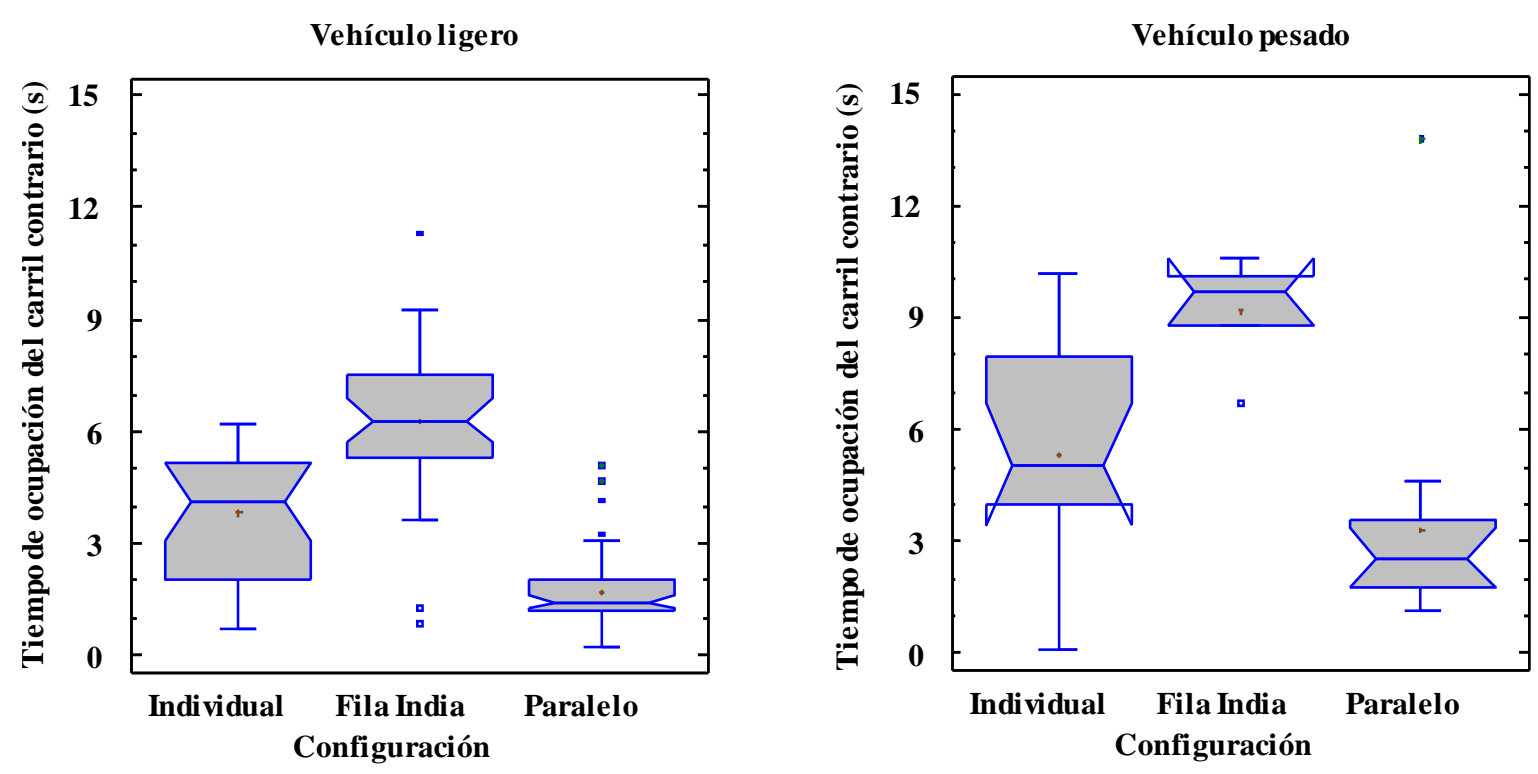

\section{Figura 5. Tiempo de ocupación del carril contrario}

nivel de riesgo percibido ( 5 es el más peligroso). Se intuye que, a la misma distancia, se percibía más riesgo cuando circulaba individualmente o cuando adelantaba un vehículo pesado. Los resultados relativos a la velocidad relativa no arrojan conclusiones claras.

Por último, se evaluó el cumplimiento de la normativa correspondiente a la mínima separación lateral durante el adelantamiento, observándose en la carretera objeto del estudio incumplimientos por parte del $2 \%, 2 \%$ y $11 \%$ de los vehículos ligeros adelantando a las bicis en configuración individual, en fila india y en paralelo, respectivamente. Estos valores ascienden a $6 \%, 20 \%$ y $14 \%$ si los vehículos que adelantan son pesados.

\section{DISCUSIÓN Y CONCLUSIONES}

El presente trabajo ha proporcionado un enfoque objetivo a la duda existente en cuanto al riesgo asociado a circular en bicicleta en distintas configuraciones o posiciones. Para ello, se han obtenido datos totalmente objetivos, como la separación lateral y la velocidad relativa, y se han comparado con la percepción subjetiva de un ciclista. En general, la configuración de la pareja de bicis (o si estas circulan de forma individual) se presenta como un factor clave en el desarrollo de la maniobra de adelantamiento por parte del tráfico motorizado.

De esta forma, cuando las bicicletas circulaban en paralelo, se observaron las menores separaciones laterales y, en consecuencia, un menor grado de cumplimiento de la mínima distancia de $1.5 \mathrm{~m}$. Sin embargo, el ciclista que participó en el estudio indica un menor nivel de riesgo percibido en esta configuración. Por otra parte, al circular en fila india, la velocidad relativa entre el vehículo a motor y la bicicleta se redujo, al mismo tiempo que la frecuencia y duración de la ocupación del carril contrario fueron mayores, sugiriendo así una mayor seguridad. La presencia de vehículos pesados se destacó también como uno de los factores más importantes por su influencia en la separación lateral y en la percepción del riesgo subjetivo. 

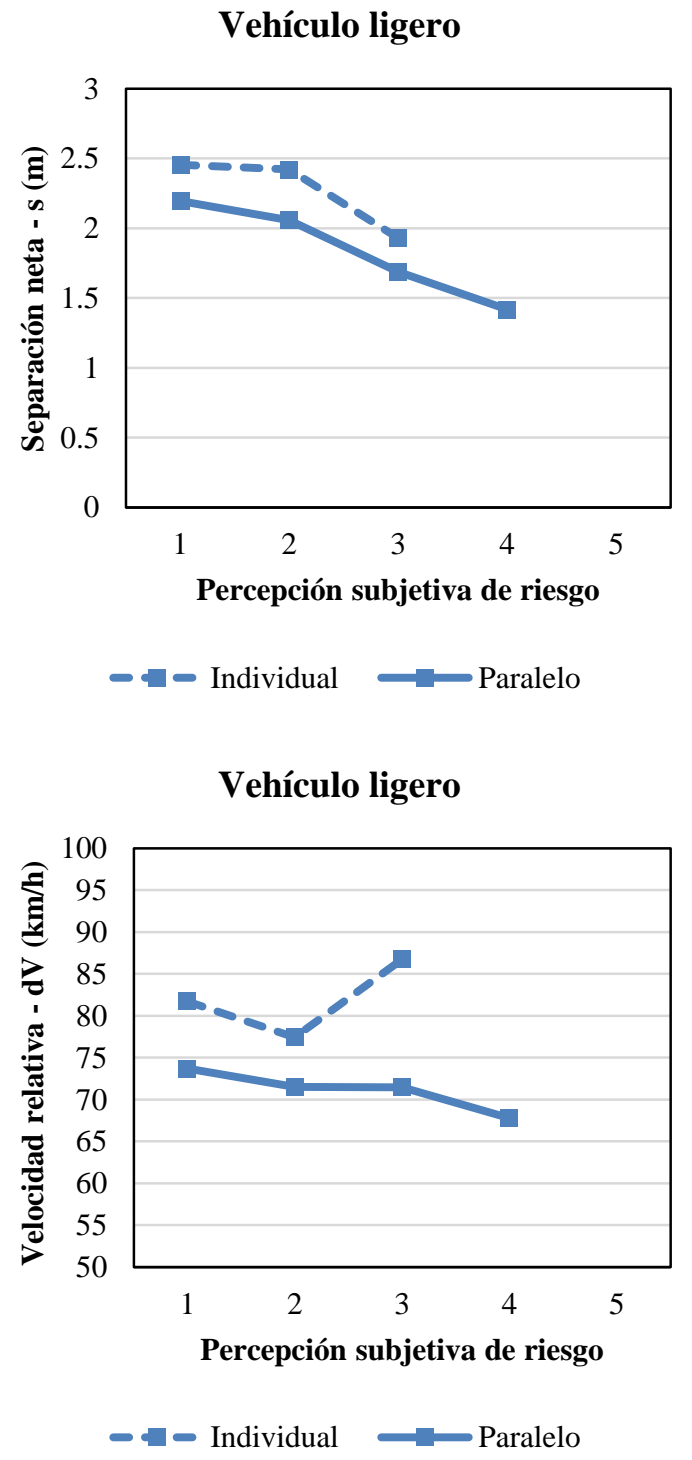
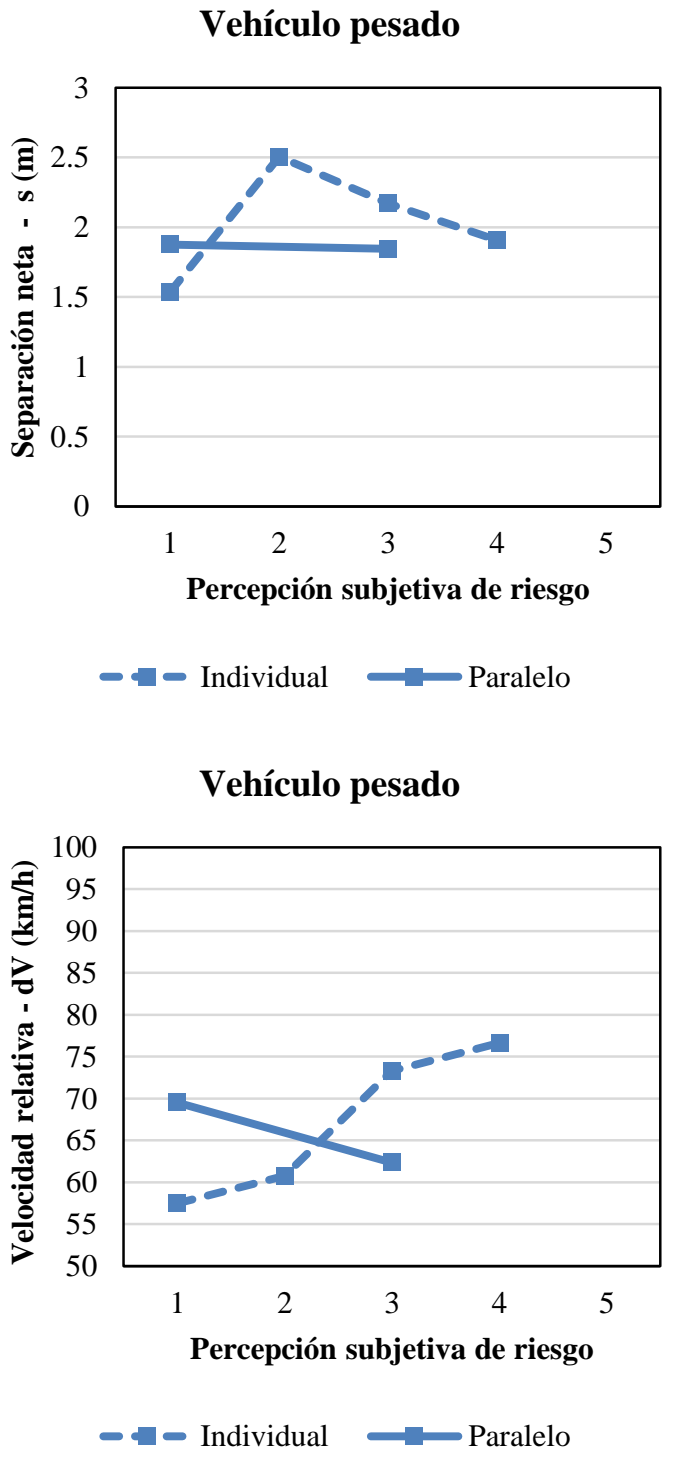

Figura 6. Percepción subjetiva (en paralelo, se corresponde con el ciclista que circula próximo al tráfico)

Las conclusiones relativas a este estudio se basan, no obstante, en una única sesión de toma de datos llevada a cabo en una única carretera. Por lo tanto, la extrapolación de estos resultados debe realizarse con precaución, en la medida las condiciones geométricas o de operación de la carretera cambien.

Próximamente, los datos obtenidos serán complementados con observaciones de adelantamientos realizados a grupos de tres ciclistas, dispuestos en distintas configuraciones de pelotón. Un análisis más profundo de los datos obtenidos tendrá como objetivo el estudio conjunto de todos los factores implicados en el fenómeno.

\section{AGRADECIMIENTOS}

Este estudio se enmarca en el proyecto "CASEFU, Estudio experimental de la funcionalidad 
y seguridad de las carreteras convencionales" con referencia TRA2013-42578-P, subvencionado por el Ministerio de Economía y Competitividad.

\section{REFERENCIAS}

Ata, M.K., Langlois, R.G., 2011. Factoring Cycling in Transportation Infrastructure : Design Considerations Based on risk Exposure. ITE J. August 201, 49-53.

Boufous, S., de Rome, L., Senserrick, T., Ivers, R., 2012. Risk factors for severe injury in cyclists involved in traffic crashes in Victoria, Australia. Accid. Anal. Prev. 49, 404-9. doi:10.1016/j.aap.2012.03.011

Chapman, J.R., Noyce, D.A., 2012. Observations of Driver Behavior During Overtaking of Bicycles on Rural Roads. Transp. Res. Rec. J. Transp. Res. Board 2321, 38-45. doi:10.3141/2321-06

Corin, R.J., He, L., Dominy, R.G., 2008. A CFD investigation into the transient aerodynamic forces on overtaking road vehicle models. J. Wind Eng. Ind. Aerodyn. 96, 1390-1411. doi:10.1016/j.jweia.2008.03.006

Llorca, C., Angel-Domenech, A., Agustin-Gomez, F., Garcia, A., 2015. Motor vehicles overtaking cyclists on two-lane rural roads: Analysis on speed and lateral clearance. Saf. Sci. doi:10.1016/j.ssci.2015.11.005

Love, D.C., Breaud, A., Burns, S., Margulies, J., Romano, M., Lawrence, R., 2012. Is the three-foot bicycle passing law working in Baltimore, Maryland? Accid. Anal. Prev. 48, 451-6. doi:10.1016/j.aap.2012.03.002

Ministerio del Interior, 2003. Real Decreto 1428/2003, de 21 de noviembre, por el que se aprueba el Reglamento General de Circulación.

Noger, C., Regardin, C., Széchényi, E., 2005. Investigation of the transient aerodynamic phenomena associated with passing manoeuvres. J. Fluids Struct. 21, 231-241. doi:10.1016/j.jfluidstructs.2005.05.013

Uystepruyst, D., Krajnović, S., 2013. Numerical simulation of the transient aerodynamic phenomena induced by passing manoeuvres. J. Wind Eng. Ind. Aerodyn. 114, 62-71. doi:10.1016/j.jweia.2012.12.018

Walker, I., 2007. Drivers overtaking bicyclists: objective data on the effects of riding position, helmet use, vehicle type and apparent gender. Accid. Anal. Prev. 39, 417-25. doi:10.1016/j.aap.2006.08.010 